\title{
Employing Electromagnetic Induction Technique for the Assessment of Soil Compaction
}

\author{
Khalid A. Al-Gaadi \\ Depterment of Agricultural Engineering, Precision Agriculture Research Chair, \\ College of Food and Agriculture Sciences, King Saud University, P.O. Box 2460, Riyadh 11451, Saudi Arabia
}

Received 2012-09-09, Revised 2012-10-10; Accepted 2012-11-07

\begin{abstract}
An experiment on a sandy soil field was conducted to investigate the potential of determining soil compaction from apparent soil Electrical Conductivity $\left(\mathrm{EC}_{\mathrm{a}}\right)$ measured by Electromagnetic Induction (EMI) technique. A soil conductivity meter (EM38) was used to measure $\mathrm{EC}_{\mathrm{a}}$ under four soil Moisture Contents (MC) (4.965.336.94 and 8.0\%) and a range of Soil Compaction (SC) levels (on the average, from 220 to $2070 \mathrm{kPa}$ ). At each MC and SC level, EM38 measurements were recorded at three EM38 heights above the ground $(0,20$ and $40 \mathrm{~cm})$ and at vertical and horizontal device orientation. Except at the MC of $8.0 \%$, results revealed that the measured $\mathrm{EC}_{\mathrm{a}}$ was proportional to $\mathrm{SC}$ at all considered soil conditions and modes of measurement (EM38 orientation and height). For all soil conditions and modes of measurement, an overall mean of the coefficient of correlation $\left(\mathrm{R}^{2}\right)$ of 0.66 was observed between $\mathrm{SC}$ and $\mathrm{EC}_{\mathrm{a}}$ at soil MC of up to $6.94 \%$. Thus, $\mathrm{EC}_{\mathrm{a}}$ measurement can be an indicator of soil compaction, given that the $\mathrm{MC}$ is below

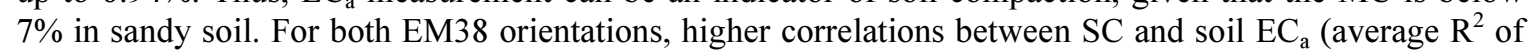
$0.90)$ were observed with the EM38 placed on the ground ( $0 \mathrm{~cm}$ height) compared to those achieved at 20 $\mathrm{cm}$ and $40 \mathrm{~cm}$ height, where the average $\mathrm{R}^{2}$ values were 0.62 and 0.47 , respectively. At $0 \mathrm{~cm}$ height and MC of up to $6.94 \%$, higher correlations between $\mathrm{SC}$ and $\mathrm{EC}_{\mathrm{a}}$ were obtained at vertical EM38 orientation (average $\mathrm{R}^{2}$ of 0.98 ) compared to those at horizontal orientation (average $\mathrm{R}^{2}$ of 0.81 ).
\end{abstract}

Keywords: Electromagnetic Induction, EM38, Soil Compaction, Soil Electrical Conductivity, Precision Agriculture, Moisture Content

\section{INTRODUCTION}

Soil Compaction (SC), which is one of the physical soil properties, refers to the increase in soil density and strength and the reduction in soil macro-pores. Extensive use of heavy agricultural machineries can greatly contribute into the increase of SC in agricultural fields (Alexandrou et al., 2002). Excessive SC exerts detrimental effects on crop production as it creates poor environment for root growth (poor aeration and excessive soil strength), reduces water infiltration and increases runoff, hence increases soil erosion. Krajco (2007) reported that soil was endangered by SC, as one of the various degradation processes that worked within the topsoil or subsoil layers. Compaction can restrict and interfere with root growth, reduce the amount and size of soil pores, decrease soil infiltration, cause water-logging and lead to run-off. This was emphasized by Hoefer et al. (2010) who stated that higher soil strength, accompanied with higher soil penetration resistances, was considered as a limiting factor for root growth as it resulted in a lack of water and nutrient supply and caused poorer plant growth and higher vulnerability of the crop to diseases. In a similar study, Kulkarni (2003) stated the negative effects of soil compaction, which included the prevention of root growth and development of plants, reduction of water infiltration as compacted soil offered smaller pores and fewer natural channels, increase of surface wetness, runoff and erosion.

Conventional methods used for SC assessment, such as cone penetrometers, can provide accurate measurements. However, these conventional procedures for compaction measurement are characterized as time consuming, labor intensive and costly. Alternatively, in- 
situ measurement of the apparent soil Electrical Conductivity $\left(\mathrm{EC}_{\mathrm{a}}\right)$ using Electromagnetic Induction (EMI) technique is viewed as one of the most efficient non-contact methods that can be used to determine various soil properties. The soil $\mathrm{EC}_{\mathrm{a}}$ is influenced by a combination of physico-chemical properties, including soluble salts, soil texture, clay content and mineralogy, soil water content, Cation Exchange Capacity (CEC), soil bulk density and compaction, organic matter, soil temperature and subsoil characteristics (Corwin and Lesch, 2003; 2005; Grisso et al., 2009; Krajco, 2007; Pozdnyakova, 1999; Edward et al., 2003; Padhi and Misra, 2009). It is evident that SC was considered, by several studies, as one of the key factors affecting the value of soil $\mathrm{EC}_{\mathrm{a}}$. Therefore, measurement of soil $\mathrm{EC}_{\mathrm{a}}$ can be used as a direct indication of SC. However, it is important to understand the factors, for a specific soil, that have the largest influence on $\mathrm{EC}_{\mathrm{a}}$ measurements. Corwin and Lesch (2003) reported that, for saline soils, salinity dominated the $\mathrm{EC}_{\mathrm{a}}$ measurements and interpretations were often more straightforward. Estimation of SC with electrical signal is becoming increasingly viable as commercial and technological solution in the construction of highway embankments, earth dams and many other engineering structures (Chik and Islam, 2011). The performance of newly developed SC measurement techniques based on soil Electrical Conductivity (EC) system is thought to be reliable and robust. This was affirmed by Seladji et al. (2010) who stated that, among the geophysical tools used in soil science, electrical methods were considered as potentially useful to characterize SC intensity. This was attributed to the fact that the analysis of the petrophysical parameters derived from their experimental data suggested that the electrical tortuosity of the loamy agricultural soil was significantly affected by compaction. Compared with traditional methods of observing soil subsurface layer, electromagnetic induction techniques were noninvasive, less labor intensive and more economical (Doolittle et al., 1994).

For efficient precision farming systems, it is important to implement cost effective and efficient methods that can enhance the process of monitoring and mapping of different soil properties, like SC. Therefore, the overall goal of this study was to explore the possibility of using Electromagnetic Induction (EMI) technique for the assessment of SC. The specific objectives, however, are as follows:

- To assess Soil Compaction (SC) based on the EM38-measured apparent soil Electrical Conductivity $\left(\mathrm{EC}_{\mathrm{a}}\right)$

- To study the influence of soil Moisture Content (MC) on the measurements at different SC levels
- To investigate the effect of the modes of measurements (orientation of the EM38 and its height above the ground) on the data collected

\subsection{Literature Review}

Electrical Conductivity (EC) is defined as the ability of a material to transmit (conduct) electrical current and is commonly expressed in units of MilliSiemens per meter (mS/m), Grisso et al. (2009). The EC of soils is known to be proportional to the amount of moisture held by the soil particles. Therefore, low conductivity is associated with sandy soils; however, medium and high conductivities are associated with silt and clay, respectively (Fig. 1). Pozdnyakova (1999) reported that soil electrical properties were the parameters of natural and artificially created electrical fields in soils and were influenced by the distribution of mobile electrical charges, mostly inorganic ions, in soils. He also stated that relationships were developed between electrical properties and other soil physical and chemical properties, such as texture, stone content, bulk density, water content, cation exchange capacity, salinity and humus content. His results showed that the density of mobile electrical charges increased with soil compaction. Doolittle et al. (1994) defined the apparent soil conductivity as being the weighted average conductivity measurement for a column of earthen materials to a specified depth.

Krajco (2007) described the soil matter to be composed of three different environments; solid soil particles, water-filled soil pores and air-filled soil pores with different EC. Because the air is an extremely good insulator, the only three possible pathways for electrical current to flow are via: (i) solid-liquid (soil particles and pores fill with water), (ii) liquid (soil water) and (iii) straight through soil particles (Fig. 2).

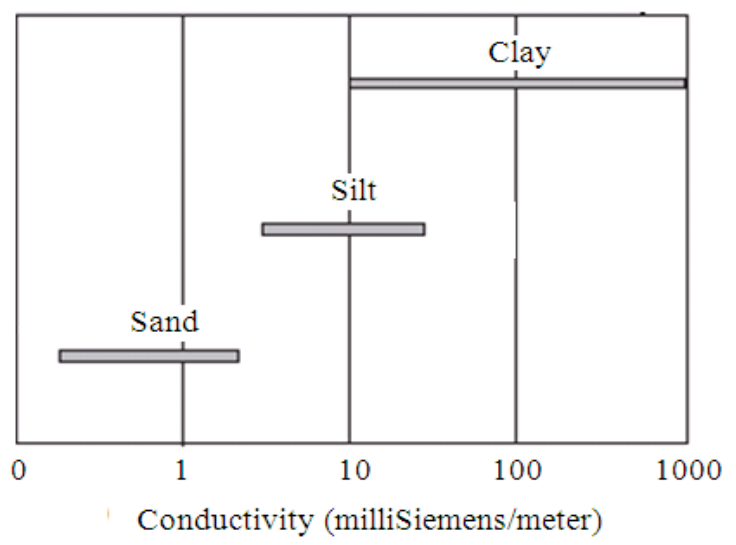

Fig. 1. Soil electrical conductivity for different soil types (Grisso et al., 2009) 


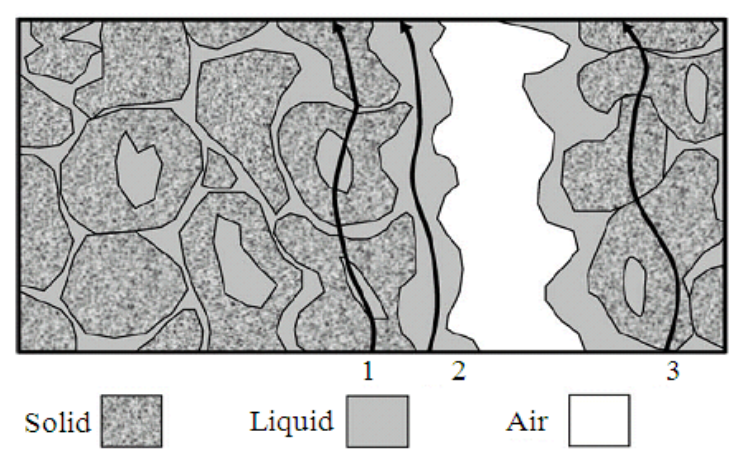

Fig. 2. Three different pathways of electrical conductance in soil (Krajco, 2007)

Soil EC is affected by various soil properties, such as soil pore connection, soil moisture, content of salts, cation exchange capacity, sensing depth and temperature (Krajco, 2007). The higher the ratio of soil pores filled with water, like in clay soils, the higher the EC. Higher moisture content provides higher conductivity, as the moisture presents the base for electrolyte by dissolving soil salts. Soil salts increase the consistency of electrolyte in soil matter, thereby, the EC. In addition, presence of positive charged ions $\left(\mathrm{Ca}, \mathrm{Mg}, \mathrm{K}, \mathrm{Na}, \mathrm{NH}_{4}\right.$ or $\mathrm{H}$ ) in water solution causes the EC to increase. For both, direct contact and EMI methods, the sensing depth negatively affects the strength of sensor signal, thereby, the accuracy of EC measurement. The temperature of soil and air was also found to affect soil EC readings.

Apparent Electrical Conductivity $\left(\mathrm{EC}_{\mathrm{a}}\right)$ of a soil profile can be used as an indirect indicator for a number of soil properties. Commercially available $\mathrm{EC}_{\mathrm{a}}$ sensors can efficiently and inexpensively develop the spatially dense datasets desirable for describing within-field spatial soil variability in precision agriculture (Sudduth et al., 2005). Electromagnetic Induction Meter (EM38), based on EMI technique, was used by many researchers in various soil applications. O'Leary et al. (2003) used an EM38 for identifying sub-soil properties. They concluded that, since electrical conductivity is well correlated with high soil water and salt content, the Electromagnetic Induction (EMI) technology coupled with accurate Global Positioning System (GPS) equipment could provide economic opportunities to map out areas of farms that are affected by subsoil constraints. According to Llewellyn and Filmer (2009), EM38-measured apparent soil Electrical Conductivity $\left(\mathrm{EC}_{\mathrm{a}}\right)$ was affected by soil moisture content, salt levels and soil texture. They also stated that, although it was necessary to analyze soil core samples to calibrate and validate EM38 measurements, EM38 mapping was particularly useful as it usually correlated well with important soil characteristics that were associated with crop yield potential. A study by Rahman (2011) revealed that $\mathrm{EC}_{\mathrm{a}}$, which was related to different soil physical properties, such as clay content, moisture content, bulk density, $\mathrm{pH}$ and salinity, can be conveniently used to determine soil spatial variability. Robinson et al. (2010) reported that as well as to salinity and soil moisture, the electromagnetic induction meter (EM38) could respond to factors including clay content, soil temperature and magnetic minerals. Pozdnyakova (1999) observed very strong exponential relationships of the electrical resistivity, which is directly related to soil $\mathrm{EC}_{\mathrm{a}}$, with soil bulk density and soil water content when measured in laboratory conditions $\left(\mathrm{R}^{2}\right.$ value ranging from 0.957 to 0.990). Hossain (2008) used an EM38 to measure soil moisture in a clay soil. His results showed that the EM38 was able to produce, in both vertical and horizontal orientation, a volumetric soil MC measurement with accuracy of approximately \pm 0.007 $\mathrm{m}^{3} / \mathrm{m}^{3}$. However, the horizontal orientation of the EM38 was, in general, found to produce better accuracies of soil moisture prediction.

Using electromagnetic induction technique, which is characterized as time and cost effective method, for the assessment of soil compaction can greatly enhance the process of SC measurement. Krajco (2007) reported that conventional methods for SC mapping, such as penetrometers, provided accurate point measurements; however, time consuming and labor intensive. On-the-go EC measurements, such as the EMI techniques represented by EM38, are affected by key soil properties including texture, $\mathrm{MC}$ and $\mathrm{SC}$ levels; therefore, can offer a possible rapid alternative for compaction detection. Hoefer et al. (2010) used an EM38 for the detection of SC and compared the EM38produced observations to soil penetration resistance measured by a penetrologger. A strong correlation was observed between the penetration resistance and the signal of the EM38, especially in the areas where high values of penetration resistance were recorded. A study was conducted by Malo et al. (2001) to determine the impact of soil moisture, bulk density and soil temperature on the measurements taken by Veris 3100 and EM38 soil sensors. A strong correlation was observed between EM38 and Veris 3100 measurements and soil MC values and to a less degree with soil bulk density and soil temperature. On the other hand, Jabro et al. (2005) compared soil penetration resistance expressed as Cone Index (CI) to the soil $\mathrm{EC}_{\mathrm{a}}$ measured using Veris 3100 and Veris 3000 sensing technologies. They found that the soil $\mathrm{EC}_{\mathrm{a}}$ and CI parameters were spatially distributed and noticed to exhibit a weak to a medium spatial dependency within the mapped field area. 


\section{MATERIALS AND METHODS}

Research field experiments were conducted on a 16 by $20 \mathrm{~m}$ plot located in the educational farm of the College of Food and Agriculture Sciences, King Saud University, Riyadh, Saudi Arabia (Fig. 3). The soil of the study field was classified as sandy soil with average soil physical and chemical properties presented in Table 1.

The apparent soil Electrical Conductivity $\left(\mathrm{EC}_{\mathrm{a}}\right)$ was measured using the soil conductivity meter EM38 of Geonics Ltd., Canada (Model: EM38-MK2-1) (Fig. 4). With an intercoil spacing of one meter, the utilized EM38 could acquire measurements for the depths of 0 to $75 \mathrm{~cm}$ and 0 to $150 \mathrm{~cm}$ in the horizontal and vertical orientations, respectively. A frame was fabricated from a PolyVinyl Chloride (PVC) pipe (Fig. 4) to provide different heights of the EM38 above the ground (0, 20 and $40 \mathrm{~cm}$ ). This was employed when investigating the effect of the device height above the ground on its response to soil $\mathrm{EC}_{\mathrm{a}}$.

A Spectrum Technologies Inc., USA (Model: Field Scout SC 900) (Fig. 5) soil compaction meter was used to measure $\mathrm{SC}$ in terms of soil resistance to penetration (Cone Index).
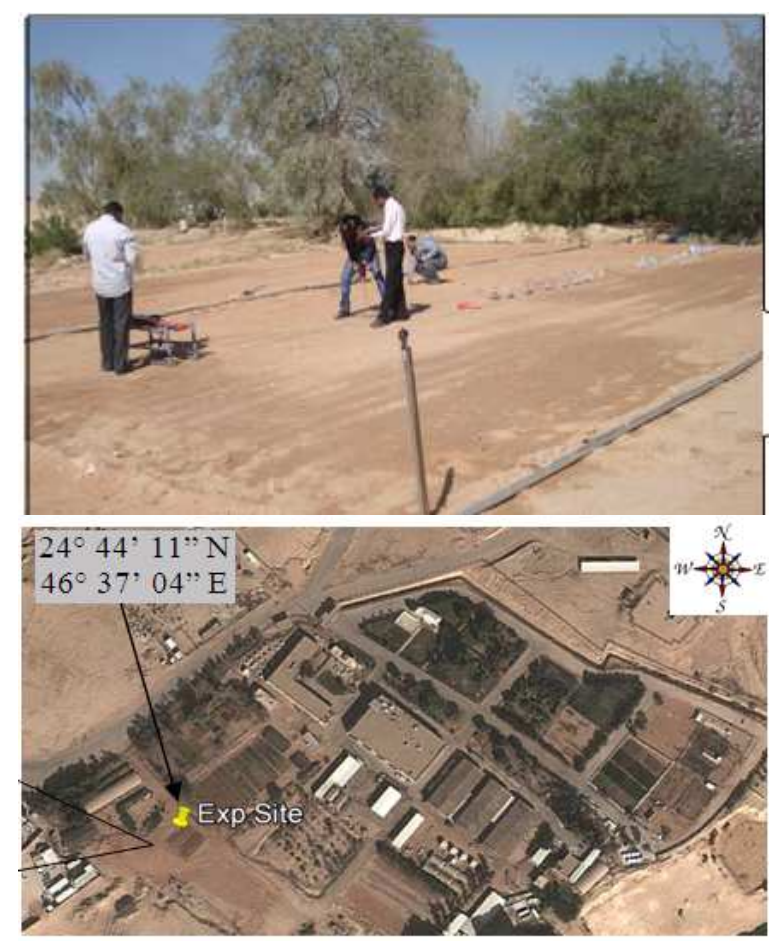

Fig. 3. The study field
Table 1. Soil properties of the study field

\begin{tabular}{ll}
\hline Soil texture & Coarse Sand $=76.4 \%$ \\
Texture class & Fine Sand $=12.3 \%$ \\
$=$ Sandy soil & Silt $=7.5 \%$ \\
& Clay $=3.8 \%$ \\
Soil field capacity $\left(\Theta_{\mathrm{fc}}\right)^{*}, \%$ & 12.88 \\
Soil wilting point $\left(\Theta_{\mathrm{wp}}\right)^{* *}, \%$ & 4.25 \\
Soil pH & 7.81 \\
Soil EC $(\mathrm{dS} / \mathrm{m})$ & 1.61 \\
\hline
\end{tabular}

*; $\Theta_{\mathrm{fc}}$ is the maximum value of water content that can be maintained without the water draining rapidly (IAEA, 2008).**; $\Theta_{\text {wp }}$ is the fraction of soil water 'held' so strongly by soil that it is not available to plants (minimum 'available' water content) (IAEA, 2008)

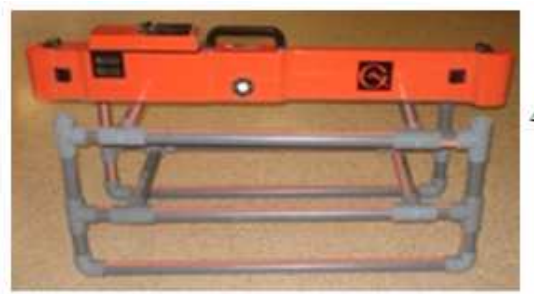

$40 \mathrm{~cm}$ height

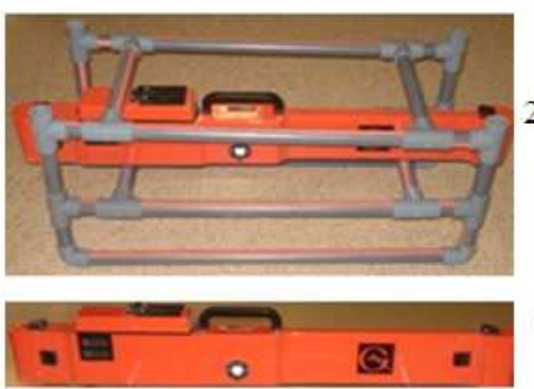

$20 \mathrm{~cm}$ height

$0 \mathrm{~cm}$ height

Fig. 4. EM38 with the frame

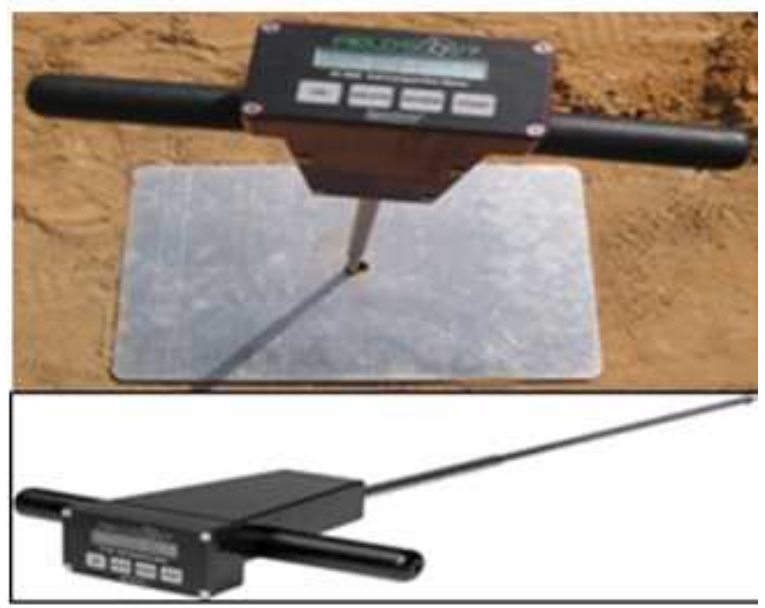

Fig. 5. The compaction meter 


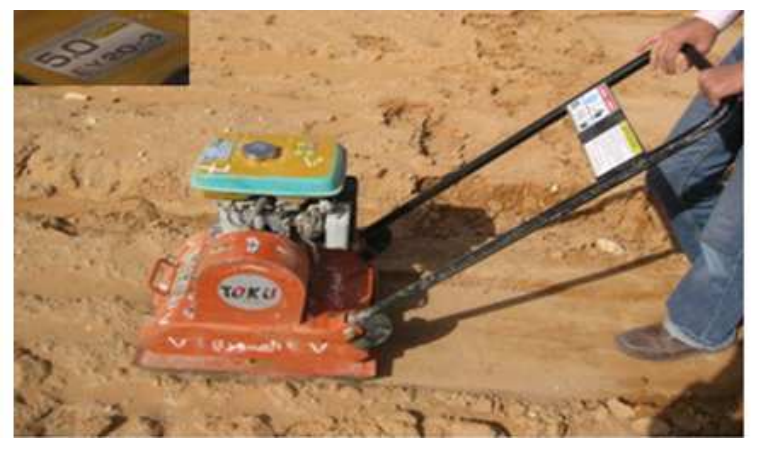

Fig. 6. The Compactor

Table 2. SC levels at different MC values

\begin{tabular}{llll}
\hline & Average soil compaction, $\mathrm{kPa}$ & \\
& $-\mathrm{Compaction}$ & $\begin{array}{l}\text { Compaction } \\
\text { level 2 }\end{array}$ & $\begin{array}{l}\text { Compaction } \\
\text { level 3 }\end{array}$ \\
\hline 4.96 & 1861.64 & 1978.06 & 2061.10 \\
5.33 & 860.42 & 1631.10 & 1841.71 \\
6.94 & 468.05 & 1304.39 & 1511.31 \\
8 & 220.61 & 867.95 & 1495.18 \\
\hline
\end{tabular}

Table 3. Soil depth ranges for ECa measurements at different EM38 heights

\begin{tabular}{llccc}
\hline & & \multicolumn{3}{c}{ EM38 Height above the ground $(\mathrm{cm})$} \\
& & Measurement range $(\mathrm{cm})$ & \\
EM38 & Intercoil & - & ---10 & \\
mode & separation & 0 & 20 & 40 \\
\hline Vertical & $1.0 \mathrm{~m}$ & 150 & 130 & 110 \\
Horizontal & $1.0 \mathrm{~m}$ & 75 & 55 & 35 \\
\hline
\end{tabular}

The compaction meter consisted of an electronic penetrometer and a built-in datalogger for storage and processing of the penetration resistance measurements. The device was equipped with an ultrasonic sensor located at the base of the meter which was used to measure the depth of penetration. The used Field Scout SC 900 compaction meter featured a measuring range of 0 to $45 \mathrm{~cm}$ and a Cone Index (CI) range of 0 to $7000 \mathrm{kPa}$.

A TOKU, Malaysia, Vibratory Plate Compactor (model: 5.0 Robin EY 20-3) (Fig. 6) was used for the purpose of obtaining different levels of SC at different soil MC values. Different MC of the field soil (averaged at 4.965.336.94 and 8\%) was obtained by applying different drying periods after irrigation. Average SC levels associated with the different average MC values are illustrated in Table 2. At each MC and SC level, three data points of soil apparent Electric Conductivity $\left(\mathrm{EC}_{\mathrm{a}}\right)$ were recorded by the EM38 adjusted at an intercoil separation of $1.0 \mathrm{~m}$ to produce maximum measurement depth of 150 and $75 \mathrm{~cm}$ for the vertical and horizontal orientation modes, respectively (Table 3). At each point, readings were taken at the three heights of the device above the ground $(0,20$ and $40 \mathrm{~cm})$ and at both orientations (vertical and horizontal) with three replicates producing 810 data points. The SC meter was used for the measurement of soil resistance to penetration (Cone Index, CI) which was used as an indicator of SC at different SC and $\mathrm{MC}$ levels. Observations were taken at $2.5 \mathrm{~cm}$ increments to a depth of $17.5 \mathrm{~cm}$.

\section{RESULTS AND DISCUSSION}

At the different moisture content values considered in this study, the EM38-measured soil $\mathrm{EC}_{\mathrm{a}}$ values were plotted versus associated $\mathrm{SC}$ values determined by the use of the SC meter (Fig. 7-10). Figure 7-9 suggest that the general trend of the relationship between $\mathrm{EC}_{\mathrm{a}}$ and soil compaction is linearly proportional with an average $\mathrm{R}^{2}$ value of 0.66 . The obtained results are in agreement with the results of several studies (Kulkarni, 2003; Sudduth et al., 2002; Hoefer et al., 2010; Rahman, 2011; Malo et al., 2001; Krajco, 2007). At MC value of $8.0 \%$ (Fig. 10), the general trend does not apply and there is no definite trend for the relationship between the two variables (soil compaction and $\mathrm{EC}_{\mathrm{a}}$ ). Therefore, the soil $\mathrm{EC}_{\mathrm{a}}$ measurement may not be used as an indicator of the soil compaction at this level of soil moisture content for the sandy soil of the study field.

The collected observations were subjected to statistical analysis using SAS software. Statistical results indicated that the measured soil $\mathrm{EC}_{\mathrm{a}}$ values produced by the EM38 oriented vertically were significantly affected by the level of $S C(p<0.05)$. In contrary, the effect of the $\mathrm{SC}$ level on the $\mathrm{EC}_{\mathrm{a}}$ measured with the $\mathrm{EM} 38$ in the horizontal orientation was found to be not significant.

Figure 7-10 show that the value of the correlation coefficient of the relationship between soil $\mathrm{EC}_{\mathrm{a}}$ and soil compaction varies depending on the level of soil moisture and mode of measurement (EM38 orientation and height above soil surface). To study the influence of soil Moisture Content (MC) and EM38 measurement mode on the relationship between soil compaction and $\mathrm{EC}_{\mathrm{a}}$, the values of the correlation coefficient $\left(\mathrm{R}^{2}\right)$ under all moisture levels were plotted versus EM38 height (Fig. 11). Figure 11 shows that the correlation trend was not affected by the soil moisture level up to an MC of $6.94 \%$. At an MC value of $8.0 \%$, absence of the general trend was observed. This was attributed to the 
assumption that, at this MC level in sandy soil, the effect of soil moisture may have dominated the effect of soil compaction on $\mathrm{EC}_{\mathrm{a}}$ measurements. In relation, Seladji et al. (2010) showed that soil resistivity was sensitive to density increase for gravimetric water contents lower than $0.25 \mathrm{gg}^{-1}$. Consequently, they suggested that the study and the monitoring of soil compaction in the field had to be conducted for soils in a dry state. Excluding data associated with MC value of $8.0 \%$ from the discussion hereafter, higher correlation between soil compaction and $\mathrm{EC}_{\mathrm{a}}$ can be obtained with the EM38 operated in the vertical orientation at $0 \mathrm{~cm}$ height at all $\mathrm{MC}$ values. The highest $\mathrm{R}^{2}$ value of almost 1.0 was observed when the EM38 was operated vertically on the soil surface at an MC value of $6.94 \%$. At $0 \mathrm{~cm}$ height, the average values of the correlation factors between $\mathrm{SC}$ and $\mathrm{EC}_{\mathrm{a}}$ across all soil MC values were 0.98 and 0.81 for the vertical and the horizontal orientation, respectively. Therefore, it can be generalized that higher correlation can be produced when the EM38 operated vertically and placed on the soil surface (i.e., at $0 \mathrm{~cm}$ height above the ground). This is in part consistent with the results obtained by Doolittle et al. (1994). However, the horizontal orientation of the EM38 produced, on the average, higher $\mathrm{R}^{2}$ values at $20 \mathrm{~cm}$ height across all MC levels (Fig. 11). On the contrary, Krajco (2007) stated that the contact-less device EM38 operated in horizontal mode was able to distinguish the areas with no compaction above $0.3 \mathrm{~m}$ with less precision and that when EM38 operated in vertical mode; it had no sufficient sensitivity to distinguish the soil with different bulk densities.

The average values of the correlation factors between soil compaction and $\mathrm{EC}_{\mathrm{a}}$ across all soil moisture values and EM38 orientations were determined. On the average, positioning the EM38 on the ground $\left(0 \mathrm{~cm}\right.$ height) produced the highest $\mathrm{R}^{2}$ value $(0.90)$ at all other soil conditions and modes of measurement compared to those produced at $20 \mathrm{~cm}$ and $40 \mathrm{~cm}$ heights (0.62 and 0.47 , respectively).

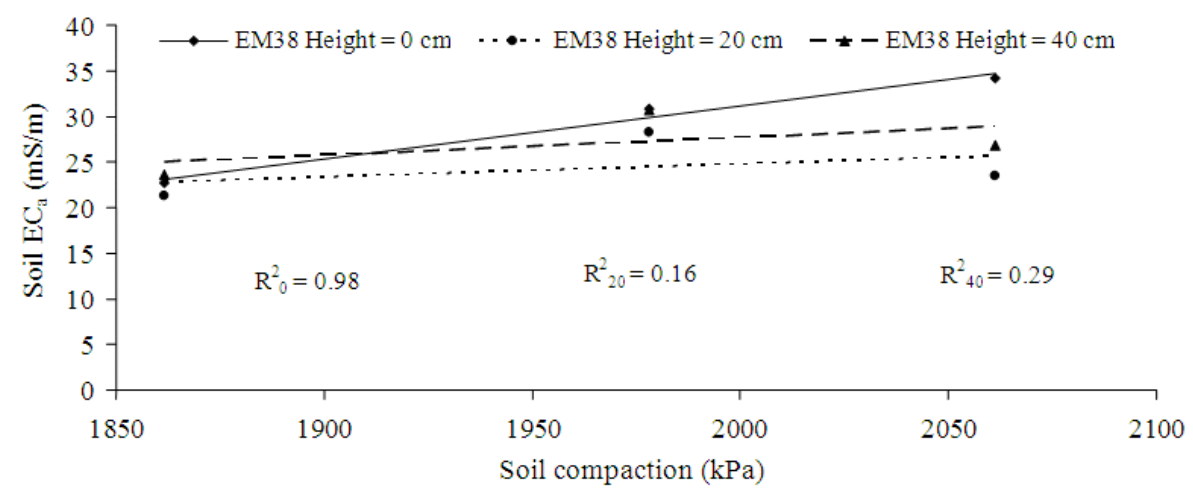

(a)

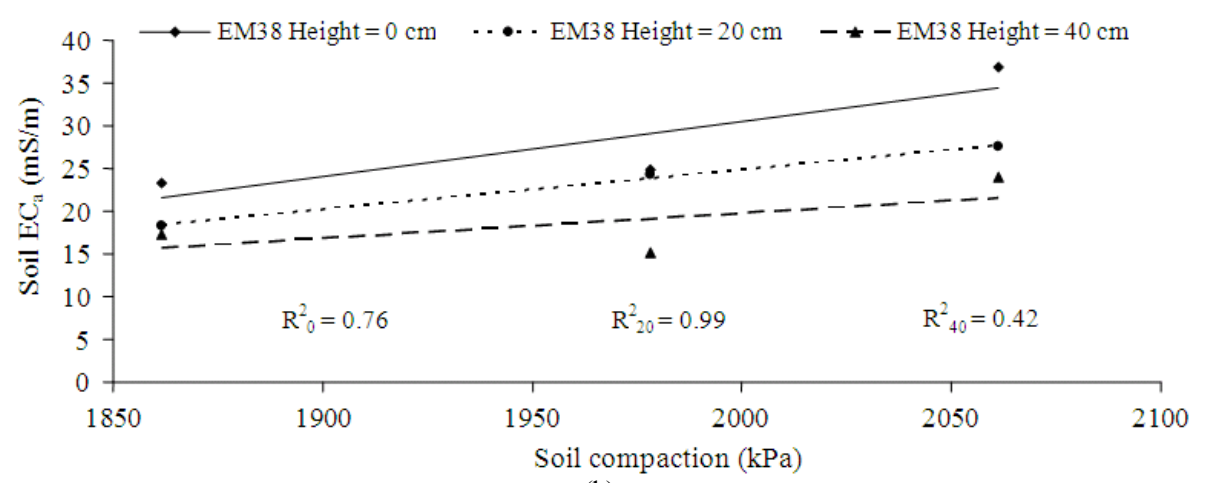

(b)

Fig. 7. $\mathrm{EC}_{\mathrm{a}} \mathrm{Vs} \mathrm{SC}$ at soil MC of $4.96 \%$ for (a) vertical and (b) horizontal EM38 orientation 
Khalid A. Al-Gaadi / American Journal of Agricultural and Biological Sciences 7 (4) (2012) 425-434

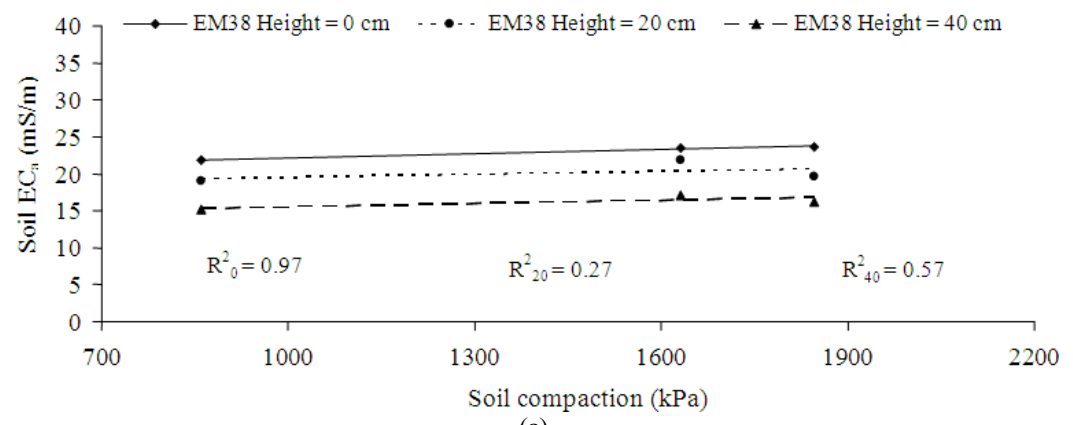

(a)

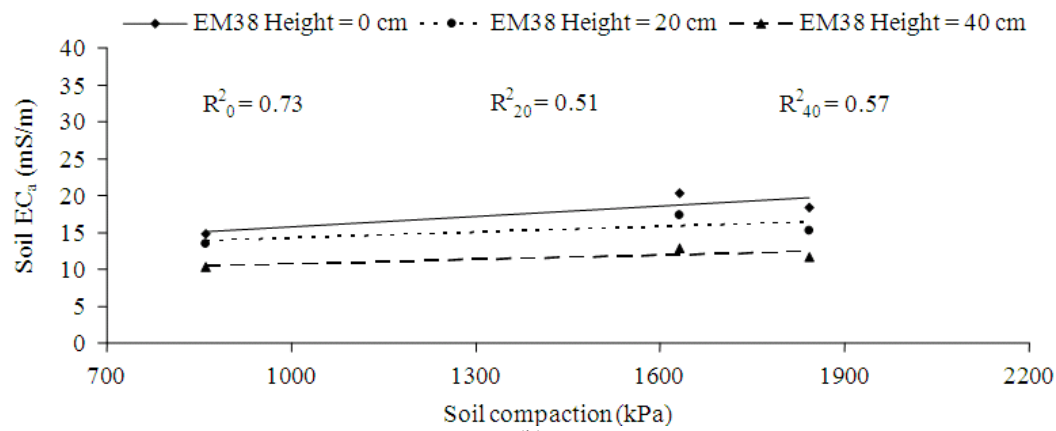

(b)

Fig. 8. $\mathrm{EC}_{\mathrm{a}}$ Vs SC at soil MC of $5.33 \%$ for (a) vertical and (b) horizontal EM38 orientation

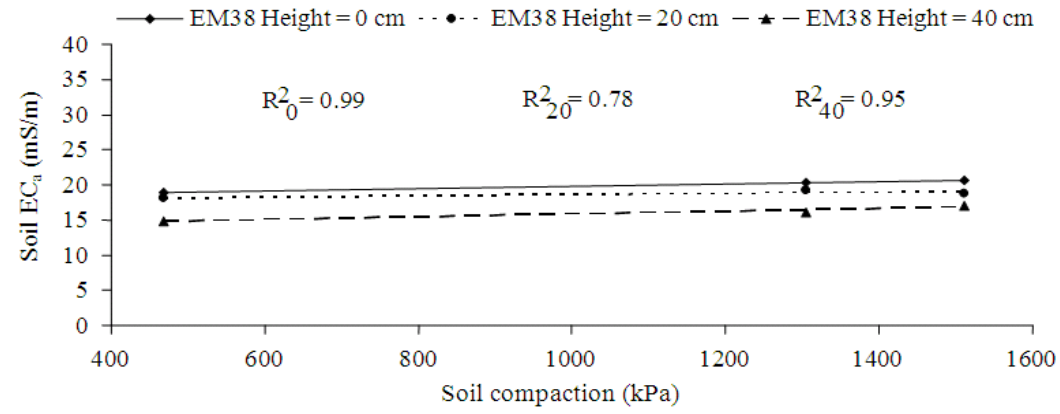

(a)

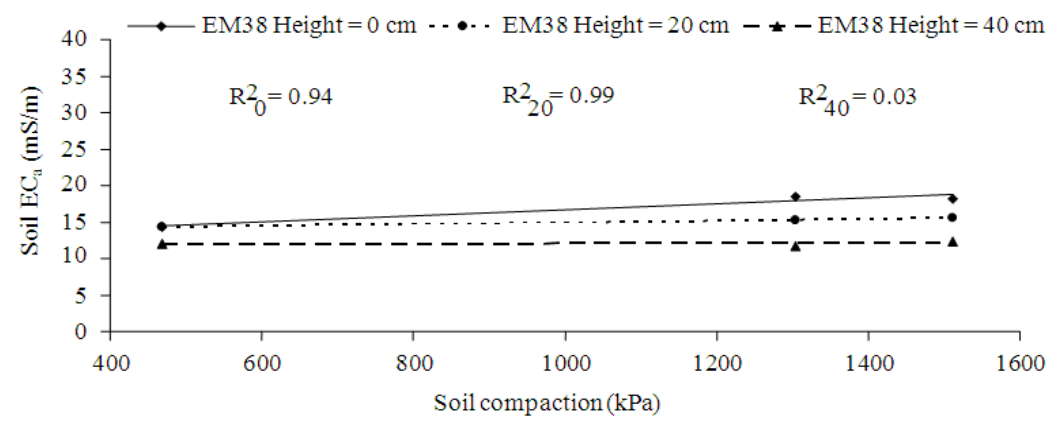

(b)

Fig. 9. ECa Vs SC at soil MC of $6.94 \%$ for (a) vertical and (b) horizontal EM38 orientation 
Khalid A. Al-Gaadi / American Journal of Agricultural and Biological Sciences 7 (4) (2012) 425-434

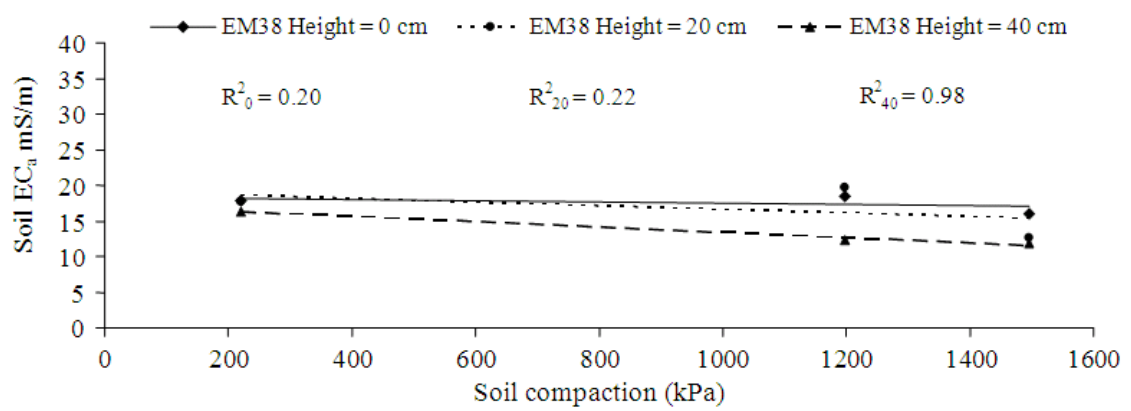

(a)

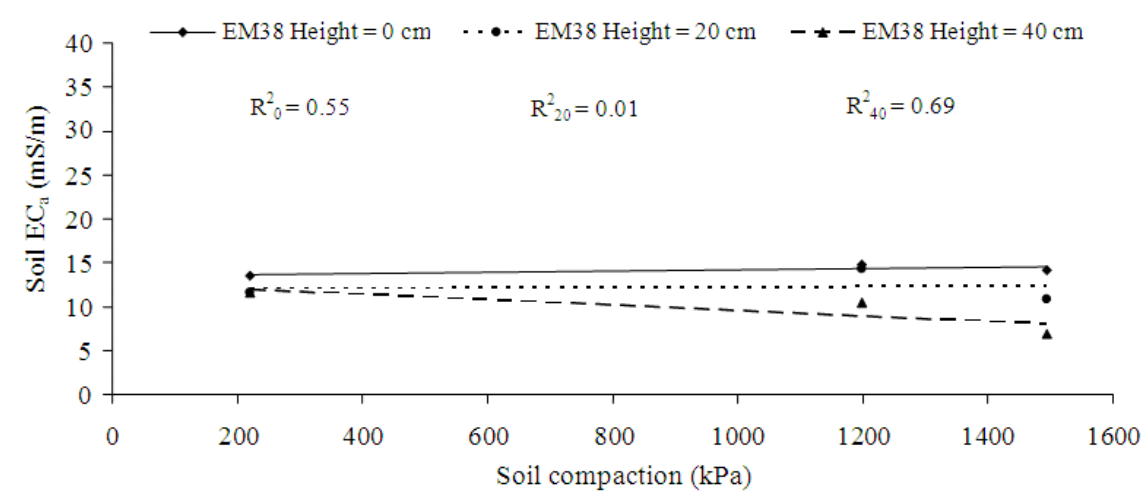

(b)

Fig. 10. $\mathrm{EC}_{\mathrm{a}} \mathrm{Vs} \mathrm{SC}$ at soil MC of $8.0 \%$ for (a) vertical and (b) horizontal EM38 orientation

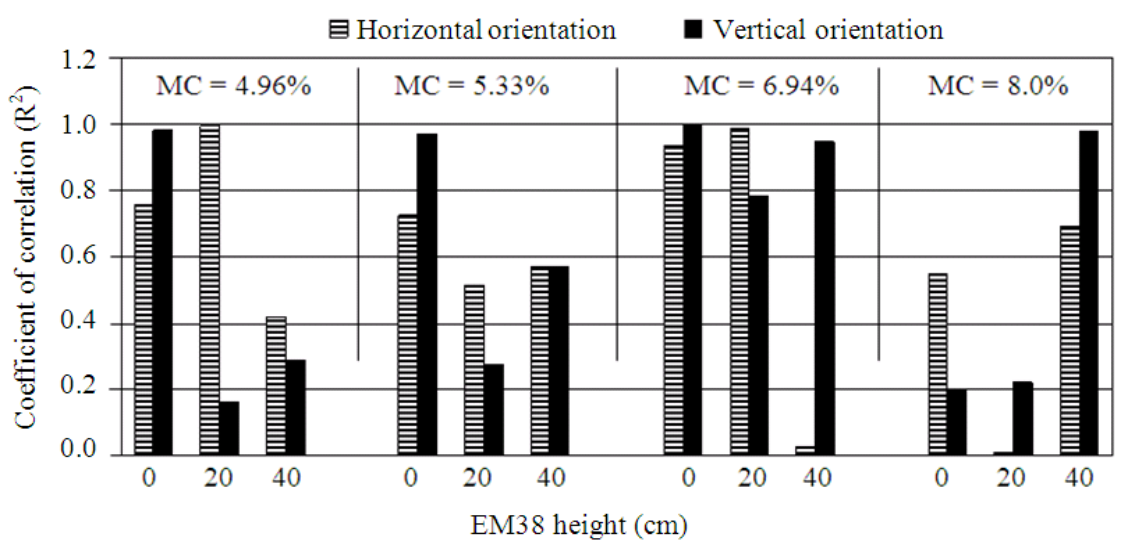

Fig. 11. Effect of soil MC and EM38 measurement mode on the $\mathrm{R}^{2}$ value of the relationship between $\mathrm{SC}$ and $\mathrm{EC}_{\mathrm{a}}$

This was attributed to the fact that lifting EM38 above the ground induced a significant decrease in $\mathrm{EC}_{\mathrm{a}}$ measurements in both orientations of the EM38 (Sudduth et al., 2002). Statistical analysis showed high significant differences $(\mathrm{p}<0.001)$ between $\mathrm{EC}_{\mathrm{a}}$ values at different EM38 heights above the soil surface. Padhi and
Misra (2009) used EM38 to monitor soil moisture and observed that the values of the $\mathrm{EC}_{\mathrm{a}}$ in the horizontal mode appeared to decrease more rapidly with increasing EM38 height above the ground than in the vertical mode. That was attributed to the difference in effective response depth, which represented less soil water. They also observed that 
the $\mathrm{EC}_{\mathrm{a}}$ changed linearly with soil water when EM38 was placed at $0.1 \mathrm{~m}$ height above the ground, but exponentially when it was placed at $0.4 \mathrm{~m}$ height above the ground. Robinson et al. (2010) stated that raising EM38 to higher positions slightly reduced sensitivity. They attributed the effect of $\mathrm{EM} 38$ height on $\mathrm{EC}_{\mathrm{a}}$ values to the smaller volume of the sampled soil as the height of EM38 increased. Due to the difference in weighting functions, the horizontal dipole $\mathrm{EC}_{\mathrm{a}}$ reading decreased more quickly with height above ground than the vertical dipole $\mathrm{EC}_{\mathrm{a}}$ reading (Sudduth et al., 2002).

\section{CONCLUSION}

A field study was conducted to explore the possibility of assessing Soil Compaction (SC) by measurement of apparent soil Electrical Conductivity $\left(\mathrm{EC}_{\mathrm{a}}\right)$ using EM38. In general, soil $\mathrm{EC}_{\mathrm{a}}$ was found to positively correlate with $\mathrm{SC}$. Hence, $\mathrm{EC}_{\mathrm{a}}$ measurement could provide a potential for an effective and efficient means of SC assessment. Specific conclusions of the study include the following:

- The $\mathrm{EC}_{\mathrm{a}}$ was found to be positively correlated with $\mathrm{SC}$. The overall mean of the $\mathrm{R}^{2}$ value of the relationship between $\mathrm{EC}_{\mathrm{a}}$ and $\mathrm{SC}$ was 0.66

- High correlations between $\mathrm{SC}$ and $\mathrm{EC}_{\mathrm{a}}$ values were observed for soil MC values of up to $6.94 \%$. At a higher $\mathrm{MC}$ value of $8.0 \%$, low correlations were observed. Therefore, for a better assessment of soil compaction, it is recommended to acquire EM38 measurements at low soil MC values (less than 7\% in case of sandy soils)

- For EM38 vertical and horizontal orientations, higher correlations between $\mathrm{SC}$ and $\mathrm{EC}_{\mathrm{a}}$ were observed when the EM38 was placed on the ground (EM38 height of $0 \mathrm{~cm}$ ) with an average $\mathrm{R}^{2}$ value of 0.90 . The average $R^{2}$ values of 0.62 and 0.47 were obtained for 20 and $40 \mathrm{~cm}$ heights, respectively

- At $0 \mathrm{~cm}$ height, vertical orientation was found to produce, on the average, a better correlation between $\mathrm{SC}$ and $\mathrm{EC}_{\mathrm{a}}$. An average $\mathrm{R}^{2}$ value of 0.98 was achieved with vertical orientation compared to 0.81 with horizontal orientation

\section{REFERENCES}

Alexandrou, A.A., R. Earl and T.A. Gemtos, 2002. In situ assessment of soil compactibility. Proceedings of the CIGR 15th World Congress ASAE Annual International Meeting, Chicago, Illinois, USA., pp: 021088-021088.
Chik, Z. and T. Islam, 2011. Tomography analysis of compacted soil using electrical conductivity. Proceedings of the World Congress Engineering, Jul. 6-8, London, UK., pp: 1403-1405.

Corwin, D.L. and S.M. Lesch, 2003. Application of soil electrical conductivity to precision agriculture: Theory, principles and guidelines. Agronomy J., 95: 455-471.

Corwin, D.L. and S.M. Lesch, 2005. Apparent soil electrical conductivity measurements in agriculture. Comput. Elect. Agric., 46: 11-43. DOI: 10.1016/j.compag.2004.10.005

Doolittle, J.A., K.A. Sudduth, N.R. Kitchen and S.J. Indorante, 1994. Estimating depths to claypans using electromagnetic induction methods. J. Soil Water Conserv., 49: 512-515.

Edward, M.B., A.S. Kenneth, W.H. John, M.L. Scott and L.C. Dennis et al., 2003. Remote- and ground-based sensor techniques to map soil properties. Photogr. Eng. Remote Sens., 69: 619-630.

Grisso, R., M.M. Alley, D. Holshouser and W. Thomason, 2009. Precision farming tools: Soil electrical conductivity. Virginia Polytechnic Institute and State University, Virginia State.

Hoefer, G., J. Bachmann and K.H. Hartge, 2010. Can the EM38 probe detect spatial patterns of subsoil compaction? Proximal Soil Sens., 1: 265-273. DOI: 10.1007/978-90-481-8859-8_22

Hossain, M.B., 2008. EM38 for measuring and mapping soil moisture in cracking clay soil. Ph.D. Thesis, University of New England, Armidale, New South Wales, Australia.

IAEA, 2008. Field Estimation of Soil Water Content: A Practical Guide to Methods, Instrumentation and Sensor Technology. 1st Edn., International Atomic Energy Agency, Vienna, pp: 131.

Jabro, J.D., Y. Kim, R.G. Evans, Y. Kim, B.W. Stevens and W. Iversen, 2005. Spatial variability of apparent electrical conductivity and cone index as measured with sensing technologies: Assessment and comparison. Proceedings of the Pacific Northwest ASAE Section Meeting, Sept. 22-24, Lethbridge, Alberta, Canada.

Krajco, J., 2007. Detection of soil compaction using soil electrical conductivity. M.Sc. Thesis, Cranfield University.

Kulkarni, S., 2003. Soil compaction modeling in cotton. AAES Res. Series, 521: 68-70.

Llewellyn, R. and M. Filmer, 2009. Key role for EM38 soil mapping in the Mallee. Farm. Ahead, 204: 44-46. 
Malo, D.D., D.K. Lee, J.H. Lee, S.M. Christopherson and C.M. Cole, 2001. Soil moisture, bulk density, soil temperature and soil sensor (Veris 3100 and Geonics EM38) relationships: Part 1-Moody country site. South Dakota State University.

O'Leary, G., D. Ormesher and M. Wells, 2003. Detecting subsoil constraints on farms in the Murray Mallee. Proceedings of the 11th Australian Agronomy Conference, Feb. 2-6, ASA, Geelong, Victoria, Australia.

Padhi, J. and R.K. Misra, 2009. Monitoring spatial variation of soil moisture in crop fields with EM38. Proceedings of the Irrigation Australia Irrigation and Drainage Conference, Oct. 18-21, Irrigation Australia Ltd, Swan Hill, Australia.

Pozdnyakova, L., 1999. Electricalal properties of soils. Ph.D. Thesis, Department of Renewable Resources, University of Wyoming, USA.

Rahman, M.M., 2011. Root-zone ECa measurement with an EM38 and investigation of spatial interpolation techniques. M.Sc. Thesis, Wageningen University, Netherlands.
Robinson, J.B., D.M. Silburn, J. Foley and D. Orange, 2010. Root zone soil moisture content in a vertosol is accurately and conveniently measured by electromagnetic induction measurements with an EM38. Proceedings of the World Congress of Soil Science, Soil Solutions for a Changing World, Aug. 1-6, Brisbane, Australia, pp: 78-81.

Seladji, S., P. Cosenza, A. Tabbagh, J. Rangerd and G. Richard, 2010. The effect of compaction on soil electrical resistivity: A laboratory investigation. Eur. J. Soil Sci., 61: 1043-1055. DOI: 10.1111/j.13652389.2010.01309.x

Sudduth, K., N. Kitchen and S. Drummond, 2002. Soil strength sensing for quantifying within-field variability. Proceedings of the American Society of Agricultural Engineers Meetings Papers, Jul. 28-31, Illinois, USA.

Sudduth, K.A., N.R. Kitchen, W.J. Wieboldb, W.D. Batchelorc and G.A. Bollerod et al., 2005. Relating apparent electrical conductivity to soil properties across the north-central USA. Comput. Electr. Agric., 46: 263-283. DOI: 10.1016/j.compag.2004.11.010 